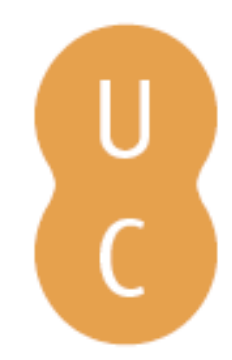

\title{
pommalina
}

\section{Universidade, ciência e "conflito de faculdades» no iluminismo e nos primórdios do liberalismo Português}

Autor(es): $\quad$ Torgal, Luís Reis

Publicado por: Imprensa da Universidade de Coimbra

URL

persistente: URI:http://hdl.handle.net/10316.2/32249

DOI: $\quad$ DOI:http://dx.doi.org/10.14195/978-989-26-0413-8_1

Accessed : $\quad$ 26-Apr-2023 07:12:21

A navegação consulta e descarregamento dos títulos inseridos nas Bibliotecas Digitais UC Digitalis, UC Pombalina e UC Impactum, pressupõem a aceitação plena e sem reservas dos Termos e Condições de Uso destas Bibliotecas Digitais, disponíveis em https://digitalis.uc.pt/pt-pt/termos.

Conforme exposto nos referidos Termos e Condições de Uso, o descarregamento de títulos de acesso restrito requer uma licença válida de autorização devendo o utilizador aceder ao(s) documento(s) a partir de um endereço de IP da instituição detentora da supramencionada licença.

Ao utilizador é apenas permitido o descarregamento para uso pessoal, pelo que o emprego do(s) título(s) descarregado(s) para outro fim, designadamente comercial, carece de autorização do respetivo autor ou editor da obra.

Na medida em que todas as obras da UC Digitalis se encontram protegidas pelo Código do Direito de Autor e Direitos Conexos e demais legislação aplicável, toda a cópia, parcial ou total, deste documento, nos casos em que é legalmente admitida, deverá conter ou fazer-se acompanhar por este aviso.

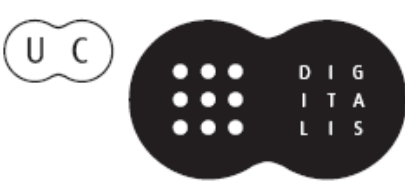


João Rui Pita

Coordenaçáo

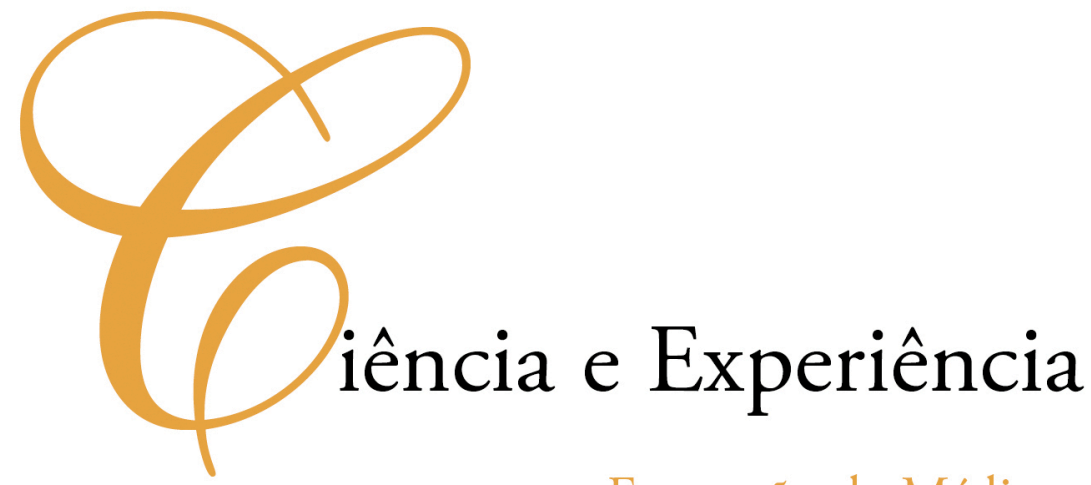

Formação de Médicos, Boticários, Naturalistas e Matemáticos

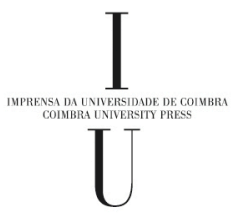

- COIMBRA 2006 


\section{Luís Reis Torgal}

Faculdade de Letras da Universidade de Coimbra;

Centro de Estudos Interdisciplinares do Século XX da Universidade de Coimbra / CEIS2O

UNIVERSIDADE, CIÊNCIA E «CONFLITO DE FACULDADES» NO ILUMINISMO E NOS PRIMÓRDIOS DO LIBERALISMO PORTUGUÊS(1)

1. O século XVIII conhece profundas transformações no campo políticocultural e científico.

O processo de consolidação do "Estado Moderno» leva a um reforço das concepções civilistas e, assim, do galicanismo, que encontrou em Febronius o seu principal expoente, divulga-se ao nível das teses oficiais, com o recuo concomitante do ultramontanismo. O desenvolvimento, a partir do século anterior, das novas concepções jusnaturalistas, com a escola holandesa e alemã - Grotius, Puffendorf, Wolff — vai também servir de fundamento às teorias do "absolutismo esclarecido", assim como as doutrinas italianas e francesas - Beccaria, Filangieri, Rousseau - servirão as concepções demoliberais. O direito romano, ainda utilizado como fundamento do absolutismo régio, vai cedendo lugar ao direito pátrio, acabando aquele por ser atacado pelo sector liberal, que o considerava um direito imperialista. A temática social e humanística - sobretudo na área da pedagogia, da história, da filologia, da linguística, da «ideologia» — passa a ser alvo de considerações científicas. As línguas modernas vão, a pouco e pouco, subalternizando as "línguas clássicas», o latim e o grego. A geografia e a economia ocupam um

\footnotetext{
(1) Adaptação para a presente obra de uma comunicação com o mesmo nome publicada na obra Claustros y estudiantes, Valência, Facultad de Derecho, 1989, vol. II, pp. 291-299.
} 
lugar cada vez mais importante no contexto de uma sociedade que aspira ao desenvolvimento. As matemáticas vão servir de base a uma concepção

de ciência rigorosa. A física, com a revolução galileana e newtoniana, ocupa um papel fundamental no universo científico. A química transforma-se numa ciência moderna. E desabrocham as ciências da vida e, com elas, desenvolve-se a medicina, que se torna, no dizer de Gusdorf, uma disciplina piloto da filosofia experimental. Procurando, enfim, captar sinteticamente os vectores desta nova dinâmica cultural, poder-se-á dizer que ela se caracteriza, de um lado, por uma certa desvalorização das ciências tradicionais - as ciências teológicas e jurídicas - ou pela alteração do seu estatuto, de modo a conferir-lhes um sentido "prático" e adaptado às novas concepções político-sociais, e, de outro, pela promoção das ciências matemáticas, da natureza e da vida, bem como das «letras» e da cultura «útil».

No âmbito desta verdadeira "revolução cultural», a «educação» teria de assumir um papel relevante. É considerada a alavanca transformadora dos povos no sentido do "progresso", da "civilização», da "felicidade» (palavras-chave da conceptologia iluminista-liberal). Difere, pois, da concepção tradicional nos seus meios e nos seus fins. Tem em vista não uma formação «metafísica», mas uma formação "prática». Ela está agora ligada aos objectivos de uma burguesia que toma consciência de classe e que vai tendo uma visão "tecnocrática» da sociedade e da cultura.

2. Esta nova situação criaria, pois, necessariamente, potencialidades para se operarem grandes transformações no plano escolar. Surge assim a ideia de um «sistema de instrução pública», que conduz à transformação dos órgãos existentes (via reformista) ou à sua supressão e substituição por novas estruturas (via revolucionária). Neste contexto, as Universidades, consideradas como órgão "corporativo-senhorial» e "eclesiástico-ultramontano», ou seriam amplamente reformadas ou extintas e substituídas por "escolas especiais».

O «absolutismo esclarecido" seguiu obviamente a via reformista e o liberalismo ou uma via ou outra, conforme o impacto e a força das ideias 
revolucionárias e conforme a solidez das estruturas universitárias tradicionais. Assim, se em França, com a Revolução, a aposta consistiu na erradicação das Universidades, em número de 24, e na criação de escolas e institutos de ensino especial com uma estrutura "pública" — só com Napoleão regressou o conceito de Universidade, apesar de diferente do conceito clássico, agora como uma super-estrutura central e centralizadora - , em Espanha e em Portugal elas mantiveram-se. No país vizinho procurou-se ainda a sua redução numérica e, em 1821, durante o triénio liberal - na continuação do liberalismo caditano - , verificaram-se transformações no domínio legal, pautadas pela concepção napoleónica, mas em Portugal, onde existia apenas uma Universidade, dotada de uma secular força tradicional, praticamente nenhuma alteração foi introduzida na sua estrutura. O que se sente na realidade universitária portuguesa durante os primórdios do liberalismo é apenas o choque das novas ideias em matéria política e de ensino e o crescendo dos «conflitos de poderes» e dos "conflitos de faculdades» que, apesar de serem ainda mais antigos, assumem uma forma diferente e mais desenvolvida a partir do reformismo iluminista do Marquês de Pombal (1750-1777).

3. Emanuel Kant escreveu de 1794 a 1797 uma pequena obra polémica intitulada Der Streit der Fakultäten (O conflito das Faculdades).

O Estado, segundo pensa - Kant reagia, assim, contra a tendência anti-iluminista de Frederico Guilherme II - procura manter a docilidade do seu povo, instalando uma cultura que garanta o seu «bem eterno», o «bem social» e o «bem corporal». Daí que, no corpo universitário, se encontrem três faculdades temporalmente dominantes, representativas do "sistema» — Teologia, Direito e Medicina. Há, porém, uma outra faculdade, a Faculdade de Filosofia, considerada como "menor", mas que é independente do Poder e do povo e que é a expressão da razão e o instrumento ao serviço da procura da verdade científica e moral. Desenvolve-se, por isso, uma luta tripla da Faculdade de Filosofia com as faculdades do Poder, que Kant analisa ao longo das três partes do seu livro. 
O filósofo alemão captou, assim, o "conflito das faculdades» que, na verdade, se trava com particular significado, embora com uma dinâmica diferente de país para país, nesse final do século XVIII. Aliás, esse "conflito» não se pode confinar a esse tempo, pois, em condições bem diversas, ele acontece em qualquer momento. Pierre Bourdieu procurou detectá-lo no seu interessante e polémico estudo da recente Universidade francesa, Homo Academicus (1984), oferecendo mesmo, com a sua metodologia de análise sociológica, algumas importantes sugestões ao historiador.

Quando se analisa o "conflito de faculdades» na Universidade portuguesa não pode deixar de se ter na devida conta - como já ficou dito - que é a reforma pombalina de 1772 o seu dinamizador fundamental. Através dos Estatutos e da legislação subsequente bem como do importante testemunho de D. Francisco de Lemos, o reitor da Universidade durante o ministério de Pombal, verifica-se, com efeito, que é o próprio Estado que pretende uma promoção da área "científico-natural", em relação à qual tem um objectivo "prático", "profissional». Não lhe bastou criar duas novas faculdades - Matemática e Filosofia — às quais sintomaticamente conferiu o estatuto de "faculdades maiores». Procurou promover o seu prestígio científico e social, o mesmo fazendo relativamente à quarta faculdade da hierarquia tradicional, Medicina, que em Portugal era encarada com desconfiança por ser frequentada por muitos cristãos novos, em relação aos quais se manteve até Pombal um estatuto de marginalização. Na realidade, não só teve o objectivo de instalar as estruturas necessárias à experimentação científica nessas áreas - Observatório Astronómico, Gabinete de Física, Laboratório Químico, Museu de História Natural (Jardim Botânico), Teatro Anatómico —, como se tentou estimular a actualização dos seus mestres através de prémios e bolsas no estrangeiro, como se procurou conferir os mesmos benefícios tradicionais que eram concedidos às outras faculdades (conezias, colegiaturas), como se desejou criar empregos para os seus diplomados. Por outro lado, medidas tomadas em relação às faculdades jurídicas vieram dinamizar outro pólo de "conflito": até 1772 frequentada maioritariamente, 
a Faculdade de Cânones foi perdendo a pouco e pouco essa vantagem a favor da Faculdade de Leis (o número de alunos desta em 1800-1801 já era o dobro do daquela).

No «absolutismo esclarecido» pombalino, e na sua sequência no período mariano-joanino, foram tomadas outras medidas responsáveis pelo potenciamento do "conflito de faculdades". Trata-se da criação - o que se integrava na lógica do reformismo iluminista - de escolas à margem da estrutura universitária (escolas profissionais, de marinha e de engenharia militar e de artes), assim como de uma superestrutura de investigação científica, com objectivos "práticos», a Academia das Ciências. Desenvolve-se assim uma elite de intelectuais de nova mentalidade, ligados ou não pela origem à Universidade de Coimbra, mas em boa parte operando fora dela, que carrilam novas concepções científicas (no plano da matemática, da filosofia natural ou da economia política) e que geralmente enveredam também pela experiência literária.

Será destes meios e das "faculdades naturais» que surgirá um grupo, restrito todavia, que se baterá pela transformação da "instrução pública» portuguesa em geral, da estrutura universitária em particular, e que apontará, assim, para a alteração das incidências culturais. O plano de instrução pública proposto por Garção Stockler na Academia das Ciências no final do século XVIII é o primeiro passo significativo dessa movimentação, que terá no triénio liberal de 20 o momento mais agitado.

4. Mas as velhas instituições contêm em si mecanismos de recuperação do "sistema» e, assim, verifica-se que, na realidade, nada se modificou de essencial na Universidade durante o Vintismo. Se as "faculdades positivas» (Teologia, Cânones e Leis) e os seus lentes tinham um capital político e social dominante até 1820, ele não foi alterado profundamente daí até 1823. Por outro lado, as «faculdades naturais», apesar da crise por que passavam, crise que era afinal a da própria Universidade em geral, mantiveram também o domínio do capital cultural e científico. 
Com efeito, os lentes juristas, sobretudo, e os lentes teólogos encontram-se em maioria nas Cortes liberais e na Comissão de Instrução Pública, criada no seu âmbito. São eles que ocupam os lugares-chave da administração universitária - o Reitor, D. Frei Francisco de São Luís, sucessor de D. Francisco de Lemos, fora opositor de Teologia e professor do Colégio das Artes (ainda que comungasse, até certo ponto, de uma cultura mais aberta a novas concepções: ele era realmente liberal desde a primeira hora, era membro da Academia das Ciências e fazia parte daquele grupo de «literatos» de ideias renovadoras); o Vice-Reitor, José Pedro da Costa Ribeiro Teixeira, era decano da Faculdade de Leis; a Directoria Geral dos Estudos, órgão administrador e fiscalizador do ensino criado em 1794 em Coimbra, era formada maioritariamente por docentes juristas e teólogos. As conezias eram ocupadas em número esmagador por juristas, os colégios eram preenchidos quase exclusivamente por opositores das faculdades de Cânones e Leis.

Por sua vez, verifica-se que o capital cultural e científico pertence essencialmente aos médicos, matemáticos e filósofos. São eles que fazem viagens de estudo pelo estrangeiro; são eles (sobretudo os de Medicina) que mais escrevem, no plano científico e não só; em 1820 dos 16 lentes de Coimbra que são sócios da Academia das Ciências (incluindo alguns jubilados), 10 pertencem às «faculdades naturais»; são eles no processo vintista que assumem as posições mais avançadas em matéria de ensino, através de propostas feitas em Cortes. José de Sá Ferreira Santos do Vale, lente de Filosofia, e Francisco Soares Franco, lente de Medicina, vão defender posições que estão na sequência do reformismo mas que se inserem também na dinâmica liberal mais avançada (Condorcet e a Convenção parecem inspirar o deputado médico na elaboração do seu "sistema de instrução pública»).

O prestígio científico e, em certa ligação, o prestígio político (em termos de ideologia e não de poder), funcionou de tal forma que as grandes críticas feitas pelos estudantes liberais, o foco verdadeiramente militante liberal de Coimbra, dirigia-se quase exclusivamente aos lentes das «faculdades posi- 
tivas», acusados de cientificamente ineptos e politicamente reaccionários, poupando no geral as "faculdades naturais", onde todavia se sentia também - conforme dissemos - uma crise científica e onde se contavam também lentes conservadores e mesmo absolutistas.

Tal facto deve-se ainda — não esqueçamos - à ligação natural das concepções jurídicas e, mesmo teológicas, à esfera política, que tornava mais perigoso para o liberalismo o ensino do velho direito, ou da velha teologia, e assim mais expostos os seus mestres. Um artigo de autor não identificado do jornal O Português Constitucional aponta claramente para esta realidade. Justificando a necessidade urgente de empreender reformas no ensino do direito, afirma, numa reflexão de sabor kantiano: "As Ciências Morais têm uma grande relação com o Governo dos Países onde elas se ensinam. As proposições quer físicas, quer matemáticas, são indiferentes com o estado político do Governo; mas o dizer quais são os direitos dos Povos, dos Reis e dos Magistrados, quais são as verdades que Deus revelou e quem pode obrar em seu nome, etc., são proposições que a opinião pública e o interesse dos que governam não deixam passar se não a seu modo; com a diferença porém que a verdade só pode reinar quando os homens escrevem o que sentem e a razão ensina, e não quando são obrigados a escrever o que o Despotismo determina. Assim os homens que então escrevem não querendo arriscar-se, ou vendo a inutilidade do seu sacrifício, cedem de boa mente à violência, que os oprime. É por esta razão que se devem reformar quanto antes certas proposições que existem nos Compêndios de Direito desta Universidade, proposições que formam uma opinião pública própria do Despotismo...»(2).

Mas, para além do corpo docente universitário, são também homens da área das "ciências naturais» estranhos a ele que debatem de forma mais sistemática os problemas do ensino, apresentando propostas concretas

\footnotetext{
(2) O Português Constitucional, nº 62, 17 de Março de 1821. Actualizámos a grafia e a pontuação do texto.
} 
relativamente à sua remodelação em Portugal e prestando sempre particular atenção à tonificação do seu vector técnico-científico. Efectivamente, poderemos destacar: Francisco Solano Constâncio, médico diplomado em Edimburgo, que nos Anais das Ciências, das Artes e das Letras - periódico publicado em Paris, de larga importância, antes e depois da Revolução de 1820, como veículo de actualização científica - procurou dinamizar em Portugal o ensino no âmbito das ciências físicas e das artes; Luís Mousinho de Albuquerque, físico-químico emigrado em França, enviava aos deputados portugueses um projecto de instrução pública pautado pelas concepções francesas pós-revolucionárias; José Pinto Rebelo de Carvalho, bacharel médico, publicava no seu jornal O Censor Provinciano, que saía em Coimbra, um artigo em que propunha um novo plano de ensino para Portugal, claramente inspirado nas concepções de Condorcet e nas experiências convencionistas.

Também na França alguns dos projectos de instrução pública mais importantes, que foram aparecendo ao longo das várias fases da Revolução, eram da autoria de intelectuais ligados às "ciências exactas" e às "ciências naturais», empenhados em posições políticas diversas. Condorcet, autor de um dos projectos de maior repercussão na França e no estrangeiro, foi o célebre matemático e "enciclopedista» que todos conhecemos; Lanthenas, que depois de Termidor publicou as «Bases fondamentales de l'Instruction publique», era médico; Fourcroy, a quem se deve a lei de educação do Consulado e o projecto imperial de Universidade, era químico, como químico era também Chaptal, que concebeu um plano de instrução que precedeu a lei de Fourcroy; Romme, que teve um papel significativo nas discussões sobre Instrução Pública, era matemático. E mesmo as outras personalidades ligadas a projectos ou que interferiram muito entusiasticamente nas polémicas sobre educação em França não pertencem ao sector dos juristas a dos teólogos integrados no «sistema». Mesmo se pertencem ao clero - como Talleyrand, Daunu ou Sieyès - assumiram dentro da ordem um papel sui generis, afastando-se das estruturas eclesiásticas tradicionais. Quanto 
a Lakanal, que teve um dos papéis mais importantes no que respeita aos problemas da instrução, era inicialmente mestre de retórica e de filosofia. $\mathrm{Na}$ Espanha, o grande projecto de Instrução Pública, que depois serviu de base à lei do ensino de 1821, deve-se ao poeta Manuel José Quintana, que também não se inseria nos esquemas culturais tradicionais.

5. Mas, como se disse, o capital político e social residia sobretudo nos juristas, não só nos lentes da Universidade, como nos que se encontravam fora dela. Eles tiveram, aliás, um papel fundamental na Revolução de 1820, o que os catapultou ainda mais para os postos do Poder. No entanto, alguns juristas, em contacto com as novas realidades, aproximavam-se nas suas concepções sócio-culturais dos «cientistas», advogando a promoção de um ensino mais "prático", afastado dos esquemas da tradição.

É assim que o ministro do Reino, Filipe Ferreira de Araújo e Castro, formado em Leis, apresentando o seu relatório nas Cortes, no princípio de 1823, afirmava significativamente, depois de ter constatado que na Universidade se tinham matriculado nas "faculdades positivas» 807 alunos, enquanto as "faculdades naturais» apenas haviam sido frequentadas por 544: «é forçoso confessar que os meios de instrução que por ora temos não estão ainda em harmonia com a ilustração do século, nem com as necessidades da Nação. A administração e a economia pública ressentem-se da falta de economistas e administradores, ao mesmo tempo que nos sobejam teólogos e juristas»(3). Mas posições destas não eram comuns e, acima de tudo, os lentes das "faculdades positivas», que constituíam uma força importante na Universidade e na vida pública portuguesa, não lutaram entusiasticamente por grandes reformas.

No decurso do liberalismo o que se vai verificar é um esforço das «faculdades jurídicas» - a partir de fins de 1836 convertidas em uma só, como consequência lógica do processo laicizador do direito - no sentido de

(3) Diário das Cortes, $2^{a}$ legislatura, t. I, pp. 322-323. 
manterem o seu poder sóciopolítico. E, apesar das críticas que sempre lhe serão movidas por estudantes inconformistas, acabarão mesmo por adquirir um capital científico mais significativo do que as «faculdades naturais». O processo tecnológico da Regeneração (a partir de 1851), no contexto de uma relativa estabilização política do regime liberal, não contará mesmo com o concurso significativo dos diplomados de Coimbra, onde as Faculdades de Matemática e de Filosofia formarão sobretudo professores ou prepararão estudantes para ingressar em outros cursos. Contudo, se a Universidade reagiu à mudança, procurando bater-se pela conservação dos seus privilégios e lutando contra a instauração de outras escolas universitárias, nomeadamente de área científica, também é certo que alguns dos seus professores até à República se foram batendo por uma renovação das «faculdades naturais» sem grande apoio governamental.

A sociedade portuguesa, apesar de alguns surtos de desenvolvimento económico-tecnológico, manteve-se durante o liberalismo essencialmente juridista e de serviços, não tendo desenvolvido as potencialidades que se encontravam contidas na dinâmica pombalina. Curiosamente, mas também sintomaticamente, ainda hoje sobrevivem em Portugal as disputas, abertas ou subterrâneas, entre técnicos e juristas, ainda que, obviamente, outros pólos de conflito surjam nos novos contextos sócio-culturais. O «conflito de faculdades», que é também um "conflito de concepções culturais», um "Conflito de sistemas de desenvolvimento" e um "conflito de estatutos de prestígio», tal como se verificou no fim do "Antigo Regime» e na época liberal, ainda não morreu de todo na sociedade portuguesa, tornando-se, contudo, mais complexo em virtude das novas realidades. Para o definir os sociólogos têm hoje um papel importante. Será esta uma das vias de trabalho da Sociologia Cultural. 